Zimmermann, C., Piccolo, L. del, Bensing, J., Bergvik, S., Haes, H. de, Eide, H., Fletcher, I., Goss, C., Heaver, C., Humphris, G., Young-Mi, K., Langewitz, W., Meeuwesen, L., Nuebling, M., Rimondini, M., Salmon, P. Dulmen, S. van, Wissow, L., Zandbelt, L., Finset, A. Coding patient emotional cues and concerns in medical

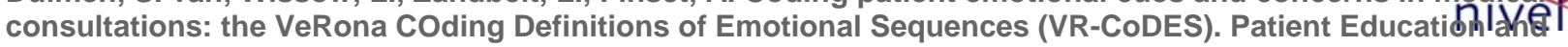
Counseling: 2011, 82(2), 141-148

\begin{tabular}{|l|l|}
\hline $\begin{array}{l}\text { Postprint } \\
\text { Version }\end{array}$ & 1.0 \\
\hline Journal website & $\underline{\text { http://linkinghub.elsevier.com/retrieve/pii/S0738-3991(10)00168-0 }}$ \\
\hline Pubmed link & $\underline{\text { http://www.ncbi.nlm.nih.gov/pubmed/20430562 }}$ \\
\hline DOI & $10.1016 / j . p e c .2010 .03 .017$ \\
\hline
\end{tabular}

This is a NIVEL certified Post Print, more info at http://www.nivel.eu

\title{
Coding patient emotional cues and concerns in medical consultations: The verona coding definitions of emotional sequences (VR-CoDES)
}

\author{
CHRISTA ZIMMERMANN ${ }^{\mathrm{A}}$, LIDIA DEL PICCOLO ${ }^{\mathrm{A}}$, JOZIEN BENSING ${ }^{\mathrm{B}}$, SVEIN BERGVIK ${ }^{\mathrm{C}}$, HANNEKE DE \\ HAES $^{\mathrm{D}}$, HILDE EIDE ${ }^{\mathrm{E}}$, IAN FLETCHER ${ }^{\mathrm{F}}$, CLAUDIA GOSS ${ }^{\mathrm{A}}$, CATHY HEAVEN ${ }^{\mathrm{G}}$, GERRY HUMPHRIS ${ }^{\mathrm{H}}$, YOUNG-Mi \\ KIM $^{\mathrm{I}}$, WOLF LANGEWITZ ${ }^{\mathrm{J}}$, LUDWIEN MEEUWESEN ${ }^{\mathrm{K}}$, MATTHIAS NUEBLING ${ }^{\mathrm{L}}$, MiCHELA RIMONDINI ${ }^{\mathrm{A}}$, PETER \\ SALMON $^{\mathrm{F}}$, SANDRA VAN DULMEN ${ }^{\mathrm{B}}$, LARRY WISSOW ${ }^{\mathrm{M}}$, LINDA ZANDBELT ${ }^{\mathrm{J}}$ AND ARNSTEIN FINSET ${ }^{\mathrm{N}}$ \\ ${ }^{a}$ Department of Medicine and Public Health, University of Verona, Verona, Italy \\ ${ }^{\mathrm{b}}$ Netherlands Institute for Health Services Research (NIVEL), Utrecht, Netherlands \\ ${ }^{\mathrm{c}}$ Department of Clinical Psychiatry, University of Troms $\varnothing$ and University Hospital of Northern Norway; \\ Tromsø, Norway \\ ${ }^{\mathrm{d}}$ Department of Medical Psychology, University of Amsterdam, Amsterdam, Netherlands \\ e Department of Nursing, Oslo University College, Oslo, Norway \\ ${ }^{f}$ Division of Clinical Psychology, University of Liverpool, Liverpool, UK \\ ${ }^{g}$ The Christie NHS Foundation Trust, Manchester, UK \\ ${ }^{\mathrm{h}}$ Health Psychology, University of St Andrews, St. Andrews, UK \\ ' JH Program for International Education in Gynaecology and Obstetrics (JHPIEGO), an affiliate of Johns \\ Hopkins University, Baltimore, USA \\ j Psychosomatic Medicine/Internal Medicine, University Hospital Basel, Basel, Switzerland \\ ${ }^{k}$ Interdisciplinary Social Science Department, Utrecht University, Utrecht, Netherlands \\ 'Empirical Consulting GmBH, Freiburg, Germany \\ ${ }^{m}$ Johns Hopkins University, Baltimore, USA \\ ${ }^{\mathrm{n}}$ Institute of Basic Medical Science, University of Oslo, Oslo, Norway
}

\begin{abstract}
Objective: To present the Verona Coding Definitions of Emotional Sequences (VR-CoDES CC), a consensus based system for coding patient expressions of emotional distress in medical consultations, defined as Cues or Concerns.

Methods: The system was developed by an international group of communication researchers. First, consensus was reached in different steps. Second, a reliability study was conducted on 20 psychiatric consultations.

Results: A Cue is defined as a verbal or non-verbal hint which suggests an underlying unpleasant emotion that lacks clarity. A Concern is defined as a clear and unambiguous expression of an unpleasant current or recent emotion that is explicitly verbalized with or without a stated issue of importance. The conceptual framework sets precise criteria for cues and concerns and for whom (health provider or patient) elicits the cue/concern. Inter-rater reliability proved satisfactory (agreement 81.5\%, Cohen's Kappa 0.70).

Conclusion: The VR-CoDES CC will facilitate comparative research on provider-patient communication sequences in which patients express emotional distress.
\end{abstract}


Zimmermann, C., Piccolo, L. del, Bensing, J., Bergvik, S., Haes, H. de, Eide, H., Fletcher, I., Goss, C., Heaver, C., Humphris, G., Young-Mi, K., Langewitz, W., Meeuwesen, L., Nuebling, M., Rimondini, M., Salmon, P. Dulmen, S. van, Wissow, L., Zandbelt, L., Finset, A. Coding patient emotional cues and concerns in medical

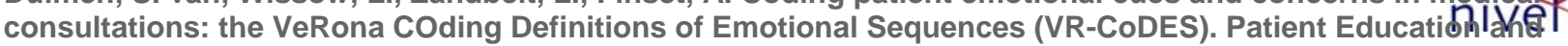
Counseling: 2011, 82(2), 141-148

Practice implications: The VR-CoDES CC may be used to help clinicians in recognizing or facilitating cues and concerns, thereby improving the recognition of patients' emotional distress, the therapeutic alliance and quality of care for these patients.

\section{INTRODUCTION}

The emotional aspects of patient-provider communication represent a crucial challenge to health providers and are among the most demanding issues for research on patient-provider interactions [1], [2], [3] and [4]. Patients' expressions of worries or emotional needs may relate to uncertainties or anxiety about their medical conditions and treatment options, but may also include concurrent life events, social problems or existential issues. There is a strong association between the number of concerns patients experience and psychological distress [5]. Recognition and acknowledgement of patients' emotional problems and distress may strengthen the therapeutic alliance [6], promote better coping with illness [7] and satisfaction [8] and reduce anxiety [3].

Emotion, although frequently present in patients with medical problems, is seldom presented directly and spontaneously in the consultation ("I am so worried about this constant pain"). It is more likely to be expressed as an indirect hint of an underlying feeling ("and then the pain really stabs me") and is therefore more difficult to detect. The literature refers to such expressions as concerns [9], [10], [11], [12] and [13], cues [3], [14], [15], [16] and [17], clues [2], empathic opportunities [1] and [18] or negative affect [19]. A range of instruments have provided categories for their identification, such as RIAS for concerns [20], CNLogit for cues [21], Medical Interview Aural System (MIARS [22]) and Medical Interaction Process System (MIPS [23]) for cues and concerns, VR-Medical Interview Classification System (VR-MICS [24]) for psychosocial cues, or Empathic Communication Coding System (ECCS [18]) for statements of emotion and challenge.

There seems to be an implicit common understanding of what is meant by cues and concerns. Yet, a recent review showed that divergent and often conflicting criteria are used to define these expressions of unpleasant emotions [25]. Attempts to compare results from studies based on different coding systems are therefore difficult. Indeed, given that limited evidence concerning the relation between the handling of cues and concerns in the medical consultation and outcomes is available yet, a consensus based system is urgently needed.

This was the first hurdle an international group of experts in health communication research, The Verona Network on Sequence Analysis, was facing when meeting in 2003 and 2004 to study critical health provider-patient communication sequences in which patients signal or express emotional distress [26]. The lack of a common ground in defining cues and concerns led to the decision to launch a consensus process on the definition of cues and concerns and, subsequently, on the definition of health provider responses to such expressions. With the purpose to facilitate comparative research on the basis of a shared language, the process gave rise to the Verona Coding Definitions of Emotional Sequences (VR-CoDES) consisting of two manuals, one for cue/concern expressions (CC) and one for health provider responses (P). Both are available on the EACH website (http:// www.each.eu.)

The aim of the present paper is to describe the results of the adopted procedural and conceptual process achieved by the Verona Network on Sequence Analysis on defining the different patient expressions of emotional distress, as illustrated in the VR-CoDES CC.

\section{METHODS}

The consensus process was initiated in 2004 and involved several steps, alternating group discussions, individual and group coding exercises within, and pilot reliability tests between the annual meetings of the Network, leading to progressive refinements of the coding definitions and the conceptual framework, as described in the proceedings of the annual Network meetings [27], [28] and [29]. The process was concluded in 2007 with the preparation of a training package for coders. A final inter-rater reliability test was carried out during 2008 on 20 psychiatric outpatient consultations.

As a first step, in 2004, the Network performed a comparative coding exercise using different coding systems. Fourteen network members, each experienced researchers in the use of one of 10 different systems known in literature (Table 1), coded the same set of six anonymized oncology and general practice 
Zimmermann, C., Piccolo, L. del, Bensing, J., Bergvik, S., Haes, H. de, Eide, H., Fletcher, I., Goss, C., Heaver, C., Humphris, G., Young-Mi, K., Langewitz, W., Meeuwesen, L., Nuebling, M., Rimondini, M., Salmon, P. Dulmen, S. van, Wissow, L., Zandbelt, L., Finset, A. Coding patient emotional cues and concerns in mealiod consultations: the VeRona COding Definitions of Emotional Sequences (VR-CoDES). Patient Educatiळ|⿰冫欠 Counseling: 2011, 82(2), 141-148

consultation transcripts. The task consisted of identifying patient turns (defined as the period when one speaker holds the floor in the interpersonal exchange [30]), containing whatever the respective system would consider an expression of worry or distress: e.g., a cue (VR-MICS; MIARS; Psychological Distress in Oncology Classification), concern, worry (RIAS), disclosure (Verbal Response Mode System [31]), or empathic opportunity (Empathic Communication Coding System; Empathic and Potential Empathic Opportunity Method).

\section{[TABLE 1.]}

The findings of the comparative coding exercise illustrated the difference between the 10 systems in how sensitive and specific they were in singling out what was regarded as an expression of worry or distress. The six consultations contained 431 patient turns. Of those 186 were selected by at least one coder as containing a cue or concern expression. Of those 51 turns were identified by at least six coders and unanimous coding of a cue or a concern occurred for only six patient turns. Thus there was uniformity only on $3 \%(6 / 186)$ of the total number of turns selected by the coders, showing that each system identified different utterances under the same heading. Despite the disconcerting results the exercise helped to identify three main interdependent aspects that had been used by the different systems, albeit inconsistently, to define patients' expression of emotional distress: (a) the emotional content of the patient expression, (b) the way of expressing the emotion either explicitly or indirectly and (c) the person (patient or health provider) triggering the cue/concern expression. These aspects offered a helpful framework within which to anchor the new consensus definitions.

Accordingly, the network decided that to be coded as a cue or concern, the patient expression should refer to an unpleasant feeling or stressful emotion or should present an issue experienced by the patient to have a distinct subjective importance and a potential negative emotional impact. The explicitness/indirectness of the emotional expression should provide a helpful criterion for a clear distinction between concerns and cues. The distinction between health provider and patient as a source of a patient's cue or concern expression was adopted to account for the fact that cues and concerns may be solicited or facilitated by the health provider or expressed spontaneously by the patient. Thus, it would offer a measure of the space for emotional issues provided by the health provider or taken by the patient's initiative. Appendix A presents the summary table of the different coding options and examples.

In the 2005 meeting the Network [27] tested a first draft of coding definitions on a series of transcripts within small groups. The final codings of each group were compared in plenary sessions. Disagreements were discussed to refine definitions and the coding criteria.

As second step in 2005 a pilot coding exercise (Table 2) took place. Fourteen coders rated one transcribed oncology consultation with the new coding definitions, differentiating between cues and concerns and between their source:patient or provider. Among the 108 patient turns, 30 expressions were coded as cues and five as concerns, with a range of 6-16 classified units per rater. None of the cues and only one concern was classified as such by all 14 raters, thus both concepts needed to be refined. Thirteen cue/concern expressions were identified as health provider initiated (HPE), and 24 as patient-elicited (PE). In respectively $10(77 \%)$ and 19 (79\%) of these at least a 50\% agreement was shown.

\section{[Table 2.]}

These findings were discussed in the 2006 meeting and led to a first revision. In particular some inclusion/exclusion criteria in the definition of cues/concerns [28] were added, such as fixing the time frame of 4 weeks to define a concern as present or recent, and counting repetitions of the same cue expression in one patient turn only once. To still better define what to consider health provider or patientelicited, it was decided to include into the definition the expression of the health provider preceding the cue or concern. To be considered as health provider-elicited a cue/concern had to be coherently and logically connected with the content of the previous health provider turn, whereas a patient-elicited cue/concern had to be introduced spontaneously by the patient without having been invited by the health provider.

As a third step, in 2006 [28] and [29], these revised definitions were applied to the same six transcripts utilized for the comparative coding exercise in 2004 by nine new raters (Table 2). The comparison showed that there was good overlap with the turns identified in 2004 by the 10 coding systems together. The 2006 version thus corresponded satisfactorily to the core summary of the different systems applied in 2004. However, three coders gave a personal interpretation of the definitions and identified a large number (61\%) 
Zimmermann, C., Piccolo, L. del, Bensing, J., Bergvik, S., Haes, H. de, Eide, H., Fletcher, I., Goss, C., Heaver, C., Humphris, G., Young-Mi, K., Langewitz, W., Meeuwesen, L., Nuebling, M., Rimondini, M., Salmon. P. Dulmen, S. van, Wissow, L., Zandbelt, L., Finset, A. Coding patient emotional cues and concerns in medicod consultations: the VeRona COding Definitions of Emotional Sequences (VR-CoDES). Patient Educationl_k Counseling: 2011, 82(2), 141-148

of turns which were not considered by the other six coders. The result was a no more than fair agreement on the majority of cue and concern expressions (Kappa $=0.48, p<0.001$ ). Regarding the distinction between health provider-elicited and patient-elicited cues and concerns, Cohen's Kappa was low (0.24-0.34). This finding called for a better specification of which provider expressions would classify a subsequent cue and concern as health provider-elicited. It was agreed to include all facilitative expressions of listening - active (e.g., echoing, checking, demanding for clarification) as well as passive ("Really?”, "Well”, "Go on”, "Tell me more") - together with empathic statements and emotion centred questions ("Do you feel stressed", "How do you feel about...?”).

Step four was a pilot reliability test in 2006-2007 which involved researchers in four different centres (Oslo, Utrecht, Amsterdam and Verona) (Table 2). Each centre applied the VR-CoDES to videotaped or transcribed consultations from their own setting: 16 videotaped nurse consultations with pain patients (Oslo), 32 and 20 videotaped internal medicine consultations (Amsterdam and Utrecht, respectively) and 20 transcribed general practice consultations (Verona). The coders achieved agreements on the distinction between cues and concerns ranging from 51 to $79 \%$ (Kappa's $0.10-0.63$ ), between cue sources ranging from 75 to $80 \%$ (Kappa's $0.42-0.58$ ) and between concern sources ranging from 59 to $74 \%$ (Kappa's from 0.38 to $0.70)$.

These findings led to step five. They showed that a detailed consensus-derived coding description was no guarantee for a satisfactory inter-rater reliability and left room for personal interpretations. To reduce potential coder bias, the Network delegated C.Z and L.D.P to design a training package for coding cues and concerns and for cue/concern related health provider responses (VR-CoDES P). The training package was tested and approved by the Network at the 2008 meeting.

A last inter-rater reliability study was conducted in 2008. Two raters, trained with the VR-CoDES exercise packages, rated twenty transcripts of a representative sample of first psychiatric outpatient consultations, drawn from a convenience sample of 104 consultations, conducted in the South Verona Community Mental Health Service. Proportion of agreement and Cohen's Kappa were adopted as reliability measures for cue/concern ratings and health provider- and patient-elicited cue/concern expressions.

\section{RESULTS: THE VR-CODES CC}

\subsection{Unit of analysis}

The full definition of the units of analysis is presented in a separate instruction manual, available on the EACH website (http:// www.each.eu). The manual also specifies the requirements for reliability assessments. In short, by unit of analysis we consider any turn or part of turn said by the patient or by the health provider, to which the codes of the two VR-CoDES systems could be applied. For the patient, the identified cue or concern determines the unit of analysis. When more than one cue/concern may be identified in the same turn, the turn has to be divided into a corresponding number of units of analysis. Turn and unit of analysis coincide when there is only one cue/concern or when identical cues or concerns are repeated within the turn.

\subsection{Definitions of cue and concern}

\subsubsection{Concern}

A concern is defined as a clear and unambiguous expression of an unpleasant current or recent emotion where the emotion is explicitly verbalized ("I am worried ..."; "I am upset”), either with a stated issue of importance for the patient ("I am so worried about my husband's illness"; "Since the illness of my husband I feel very helpless") or without a stated issue ("I am so anxious”; "I am nervous”). Included are patient expressions confirming the health provider's explicit assumption or question about an unpleasant current or recent emotion (Health Provider: “Are you anxious?”, or "You must be shocked!.” Patient: "Yes, I am.”).

Emotion is considered here as any experience related to depressive or anxious mood or to combinations of any of Ekman and Friesen's [32] list of basic emotions with a negative connotation: anger, fear, sadness, disgust, surprise in terms of shock, and shame.

To be rated a concern, there must be evidence that the concern is current, i.e. present within the last 4 weeks. 
Zimmermann, C., Piccolo, L. del, Bensing, J., Bergvik, S., Haes, H. de, Eide, H., Fletcher, I., Goss, C., Heaver C., Humphris, G., Young-Mi, K., Langewitz, W., Meeuwesen, L., Nuebling, M., Rimondini, M., Salmon, $P_{\text {. }}$ Dulmen, S. van, Wissow, L., Zandbelt, L., Finset, A. Coding patient emotional cues and concerns in mealical consultations: the VeRona COding Definitions of Emotional Sequences (VR-CoDES). Patient EducatiめIKK Counseling: 2011, 82(2), 141-148

\subsubsection{Cue}

A cue is defined as a verbal or non-verbal hint which suggests an underlying unpleasant emotion but lacks clarity. Instances include:

a. Words or phrases in which the patient uses vague or unspecified words to describe his/her emotions.

b. Verbal hints to hidden concerns (emphasizing, unusual words, unusual description of symptoms, profanities, exclamations, metaphors, ambiguous words, double negatives, expressions of uncertainties and hope).

c. Words or phrases which emphasize (verbally or non-verbally) physiological or cognitive correlates (regarding sleep, appetite, physical energy, excitement or motor slowing down, sexual desire, concentration) of unpleasant emotional states. Physiological correlates may be described by words such as weak, dizzy, tense, restless, or by reports of crying whereas cognitive correlates may be described by words such as poor concentration or poor memory.

d. Neutral expressions that mention issues of potential emotional importance which stand out from the narrative background and refer to stressful life events and conditions. This applies to nonverbal emphasis of the sentence, abrupt introduction of new content, pauses before or after the expression or to a patient-elicited repetition of a previous neutral expression in subsequent turns.

e. Non-verbal clear expressions of negative or unpleasant emotions (crying), or hints to hidden emotions (sighing, silence after provider question, trembling voice, frowning, etc.).

f. A repetition, with very similar words, of an expression said in a previous turn by the patient.

g. A clear and unambiguous expression of a concern, e.g., a previous mental state, a previous worry or fear, referring to a past episode, of more than 4 weeks ago or without a clear time frame.

\subsection{Conceptual framework for the distinction between cues and concerns}

From a biopsychosocial perspective, where the emotional and physical aspects of the patient's illness are both considered important, cues and concerns are a significant source of information on patients' fears and worries. They require different skills from the health care provider. Cues as verbal or non-verbal hints to concerns would need further clarification and, thus, information gathering and facilitating skills to help patients express their concerns. Concerns may or may not necessarily demand exploration. If not, they would rather require an empathic response or acknowledgement.

The expression of concerns, contrary to cues, helps the health provider to recognize emotional distress in patients. Moreover, concerns suggest greater accessibility of patients to their emotions. To verbalize clearly one's own feelings in the presence of an attentive and interested listener predicts competent coping [7] and [33] and feeling understood and supported increases patients' satisfaction and collaboration [33] and [34].

\subsection{Conceptual framework for the distinction between health provider-elicited (HPE) and patient- elicited (PE) cues and concerns}

Both cues and concerns may be elicited by the provider or the patient. Health provider-elicited cues and concerns indicate the provider's interest in the patient's feelings and worries and hence in a more comprehensive understanding of patients. Space is offered to patients to explicate their distress and patients do not need to take initiatives or to break conversational rules. Many patients discuss their emotional functioning only if the physician initiates the discussion [35].

\subsubsection{Defining criteria for health provider-elicited (HPE) cues/concerns}

Health provider-elicited cue/concerns are:

- coherently and logically connected with the previous health provider turn. They may be given as responses to a health provider's closed-ended questions (“Are you worried?"), to open-ended focusing questions ("What made you postpone the appointment?"; "How were your feelings?”), or to provider statements which have addressed a topic of relevance to the subsequent cue or concern.

- $\quad$ subsequent to open-ended non-focusing inviting questions by the health provider ("and then?”; "Tell me more..."), facilitations (echoing, reflections) and expressions of empathy ("this decision must have been hard for you..."). This holds also for minimal facilitations such as "hmm", "right", which signal listening and are an implicit invitation to talk. For this reason all cue and 
Zimmermann, C., Piccolo, L. del, Bensing, J., Bergvik, S., Haes, H. de, Eide, H., Fletcher, I., Goss, C., Heaver, C., Humphris, G., Young-Mi, K., Langewitz, W., Meeuwesen, L., Nuebling, M., Rimondini, M., Salmon, P. Dulmen, S. van, Wissow, L., Zandbelt, L., Finset, A. Coding patient emotional cues and concerns in mealiced consultations: the VeRona COding Definitions of Emotional Sequences (VR-CoDES). Patient Educatiめ) Counseling: 2011, 82(2), 141-148

concern expressions in a patient turn subsequent to facilitation, open-ended non-focusing, inviting question or statement of empathy should be identified as health provider-elicited also when they represent topic changes within a patient turn.

Some examples of health-provider-elicited cues/concerns include:

After a closed-ended question:

HP: “Do you feel disappointed?” P: "Yes I do.” (concern HPE);

After an open-ended focusing question:

HP: "How do you feel?” P: "I feel anxious.” (concern HPE);

HP: "How is the pain?” P: "My whole chest is in a tight band.” (cue HPE);

After a provider statement which has addressed a topic of relevance for the patient:

HP: "It is high blood pressure that is the problem.” P: "That is worrying ...” (concern HPE);

After an open-ended non-focused question which leaves space to the patient:

HP: "What's the problem?” P: "Everything seems useless...” (cue HPE);

HP: "How are you doing?” P: "I am worried about this pain.” (concern HPE). Last week I also lost my job” (cue HPE);

After a facilitation which leaves space to the patient:

HP: Right! P: "I am worried about the blood test (concern HPE) and I am upset about my daughter's car accident” (concern HPE);

After a statement of participation or empathy:

HP: “This situation seems not to be easy for you...” P: “No, it isn’t...” (cue HPE);

\subsubsection{Defining criteria for patient-elicited (PE) cues/concerns}

Patient-elicited cues/concerns are initiatives of the patient to direct the health provider's attention, sometimes unwittingly, to emotionally loaded issues, hitherto in the visit ignored or insufficiently discussed or explored. The patient introduces his/her 'emotional' agenda without having been invited or expected by the provider to do so.

These are all concerns/cues not directly connected with what was said in the previous exchange. They represent or suggest a topic change and stress the importance of the topic for the patient.

Some examples for patient-elicited cues/concerns include:

After a focusing statement:

HP: “This is the next appointment for the chemotherapy.” P: “I see... I am quite worried...” (concern PE topic change);

HP: "You are going to be all right." P: "It's so disappointing to have done all these tests and that part was never really checked" (concern PE - topic change);

After an open-ended focusing question:

HP: “What did Dr. X say?” P: “That it's gone beyond surgery. But we need to treat the whole body, we need to treat the whole body" (cue PE - emphasizing importance of topic);

After a closed-ended question:

HP: “Did the therapy improve your symptoms?” P: "Not very much. My husband complains about the high treatment expenses we had and makes me feel guilty" (concern PE, unrelated to the preceding HP turn).

\subsection{Conceptual framework for the distinction between expressions of current/recent concerns and mentions of past concerns}

Concerns of current or recent importance and any issue, related to illness or to other events, that cause worries, create apprehension, distress, anxiety or any other verbalized emotion to the patient may be associated with emotional distress of clinical significance [5]. They should alert the health provider and stimulate interventions when needed. The inclusion in the coding system of past concerns with uncertain current or recent importance would invalidate this relationship.

VR-CoDES CC has adopted the 4 weeks frame from the General Health Questionnaire (GHQ) [36]. The GHQ is one of the most widely used validated screening questionnaire for the presence of emotional distress. Yet, the distinction between recent and past concerns is not always possible. In many consultations the time frame of the concern remains unclear and cannot be deduced from the content of the conversation. 
Zimmermann, C., Piccolo, L. del, Bensing, J., Bergvik, S., Haes, H. de, Eide, H., Fletcher, I., Goss, C., Heaver C., Humphris, G., Young-Mi, K., Langewitz, W., Meeuwesen, L., Nuebling, M., Rimondini, M., Salmon, P. Dulmen, S. van, Wissow, L., Zandbelt, L., Finset, A. Coding patient emotional cues and concerns in mealical consultations: the VeRona COding Definitions of Emotional Sequences (VR-CoDES). Patient EducatiめIKK Counseling: 2011, 82(2), 141-148

In this case the patient utterance has to be coded as a cue: it would need further exploration of the time axis in order to be defined as an explicit expression of negative emotions (concern).

\subsubsection{Defining criteria for recency}

These are some rules of thumbs and examples to guide coders in defining a concern as recent:

- The concern is stated in present tense.

- $\quad$ Emotion related to issue is stated in past tense but suggests a time frame within the last 4 weeks.

"The loss of my job last week made me very upset".

- The concern is stated in the past tense but is still important for the patient. This can be understood from the context of the interview or by details offered by the patient:

HP: “The doctor suggested chemotherapy?” P: "Yes, he did. I was very frightened.” (cue PE).

HP: “Are you still frightened?” P: “Yes, I am” (concern HPE).

Where a concern without a time frame is followed by the same concern with information on its recency, the first one is coded as a cue, the second as a concern, as is shown by the last example. The time frame is irrelevant for the definition of a cue, being by definition vague and needing exploration.

\subsection{Reliability}

The inter-rater reliability of VR-CoDES CC, as tested in the final inter-rater reliability study conducted in 2008 (step 5) was satisfactory. The proportion of agreement was 81.46\%, with a Cohen's Kappa of 0.70 $( \pm 0.03)(p<0.0001)$. Similarly, the agreement regarding the distinction HPE and PE was $81.27 \%$, with a Cohen's Kappa of $0.70( \pm 0.03)(p<0.0001)$.

\section{DISCUSSION AND CONCLUSION}

\subsection{Discussion}

The Verona CoDES CC has been developed by an international group of communication researchers with a particular interest in emotionally loaded communication exchanges occurring in medical consultations. This instrument, complemented by the VR-CoDES P for health providers' cue and concern related responses, was created with the specific intent to establish consensus based definitions that would facilitate collaborative and multi-centre studies of such critical interaction sequences.

The VR-CoDES CC focuses on how patients express their emotional distress during consultations. First, as suggested by the concept adopted in MIARS [22] and PBCI [38], it makes the crucial distinction between concern and cue, defining concern as an explicit and clear verbalisation of an unpleasant emotional state and cue as a verbal or non-verbal hint to an underlying unpleasant emotion. It describes seven different instances of cues to help coders in the rather difficult task to recognize the vague and subtle expressions of potential emotional distress which include emphasized physiological or cognitive states, mentioning of stressful life events, repetitions of apparently neutral contents as well as a range of nonverbal expressions. Although these different cue manifestations might be coded and studied separately they were not intended for such a purpose. They are likely, by their very nature, to cause reliability problems, and would require large data sets for quantitative analyses. A second distinction is made between patient and health provider-elicited cues and concerns and was adopted and modified from earlier work by others [2], [3], [9], [12], [13], [14] and [23]. Combined, these two distinctions offered a useful framework for refining the definitions of the VR-CoDES CC coding categories to assess the differential informative quality of cue and concern, and the contribution of patient and health provider to the emergence of emotional issues.

Reliability data that were gathered from psychiatric consultations, showed that with trained raters agreement in coding the VR-CoDES CC was satisfactory, suggesting the feasibility and usefulness of the distinction between cue and concern and between health provider-elicited and patient-elicited cues/concerns. If these results were confirmed in other medical settings and in different countries, the system as such or in combination with the VR-CoDES P could become an important tool for research and clinical practice in improving evidenced based communication in health care. 
Zimmermann, C., Piccolo, L. del, Bensing, J., Bergvik, S., Haes, H. de, Eide, H., Fletcher, I., Goss, C., Heaver, C., Humphris, G., Young-Mi, K., Langewitz, W., Meeuwesen, L., Nuebling, M., Rimondini, M., Salmon, P. Dulmen, S. van, Wissow, L., Zandbelt, L., Finset, A. Coding patient emotional cues and concerns in mealical

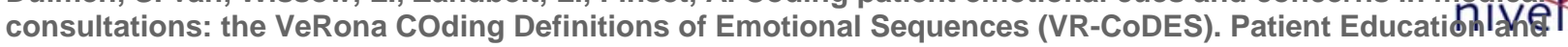
Counseling: 2011, 82(2), 141-148

\subsection{Conclusions}

Next steps might include validation of VR-CoDES results by patients reviewing their own visits. Furthermore, we expect that cue and concern expressions may be differently related to outcome variables according to their elicitation source and their context. The VR-CoDES thus has potential for providing new empirical evidence for example concerning the recognition of patient-elicited expressions most likely to indicate emotional issues and significant or sub-threshold emotional distress, or concerning the potential benefits of helping patients to disclose their emotional agenda. These, in turn, may have important implications for clinical practice.

\subsection{Practice implications}

The VR-CoDES CC was developed on the basis of consultation transcripts but can also be applied to video- or audio-recorded consultations. The system, together with the complementary VR-CoDES P for cue/concern related health provider responses [39], facilitates comparative and cross-national research on health provider-patient communication sequences in which patients signal or express emotional needs. In addition it can be used to train clinicians in recognizing and facilitating cues and the expression of concerns, thereby contributing to improve therapeutic alliance and health.

\section{INFORMATION FOR USERS}

The training package of coding exercises, developed by the network, is obtainable on request. For the correct application of the VR-CoDES, new users are strongly recommended to complete the exercises of the training package and, subsequently, to conduct a reliability study with their own transcript/video data to ensure minimal quality standards.

\section{ACKNOWLEDGEMENTS}

The VR-CoDES for patient expressions of cue and concern in medical consultations is the result of the combined efforts of a group of European and American researchers from the Verona Network on Sequence Analysis.

The consensus process was launched at the $2^{\circ}$ Verona workshop 2004 of the Network and continued throughout 2006 and 2007. The contributors were:

Jozien Bensing, Utrecht, NL; Svein Bergvik, Tromso, NO; Phyllis Butow, Sydney, AU; Carma Bylund, Chicago, USA; Lidia Del Piccolo, Verona, IT; Sanne Franssen, Amsterdam, NL; Claudia Goss, Verona, IT; Hanneke de Haes, Amsterdam, NL; Hilde Eide, Oslo, NO; Arnstein Finset, Oslo, NO; Ian Fletcher, Liverpool, UK; Claire Green, Manchester, UK; Cathy Heaven, Manchester, UK; Gerry Humphris, St. Andrews, UK; Wolf Langewitz, Basel CH; Jesse Jansen, Utrecht, NL; Young-Mi Kim, Baltimore, USA; Greg Makoul, Chicago, USA; Mariangela Mazzi, Verona, IT; Ludwien Meeuwesen, Utrecht, NL; Trond Mjaaland, Oslo, NO; Matthias Nuebling, Freiburg, DE; Monica Paccaloni, Verona, IT; Michela Rimondini, Verona, IT; Johanna Ruusuvuori, Tampere, FI; Peter Salmon, Liverpool, UK; Tonje Sibbern, Oslo, NO; Helge Skirbekk, Oslo, NO; Nicola Schofield, Manchester, UK; Myriam Shlesinger, Ramat Gan, IL; Ellen Smets, Amsterdam, NL; Sandra van Dulmen, Utrecht, NL; William Verheul, Utrecht, NL; Larry Wissow, Baltimore, USA; Linda Zandbelt, Amsterdam, NL; Christa Zimmermann, Verona, IT.

\section{REFERENCES}

[1] A.L. Suchman, K. Markakis, H.B. Beckman and R. Frankel, A model of empathic communication in the medical interview, J Am Med Assoc 277 (1997), pp. 678-682.

[2] W. Levinson, R. Horawara-Bhat and J. Lamb, A study of patient clues and physician responses in primary care and surgical settings, J Am Med Assoc 284 (2000), pp. 1021-1027.

[3] P.N. Butow, R.F. Brown, S. Gogar, M.H.N. Tattersall and S.M. Dunn, Oncologists reaction to cancer patients' verbal cues, Psycho-Oncol 11 (2002), pp. 47-58.

[4] C. Heaven, P. Maguire and C. Green, A patient-centred approach to defining and assessing interviewing competency, Epidemiol Psichiatr Soc 12 (2003), pp. 89-91.

[5] C.M. Heaven and P. Maguire, The relationship between patients' concerns and psychological distress in a hospice setting, Psycho-Oncol 7 (1998), pp. 502-507. 
Zimmermann, C., Piccolo, L. del, Bensing, J., Bergvik, S., Haes, H. de, Eide, H., Fletcher, I., Goss, C., Heaver C., Humphris, G., Young-Mi, K., Langewitz, W., Meeuwesen, L., Nuebling, M., Rimondini, M., Salmon, P. Dulmen, S. van, Wissow, L., Zandbelt, L., Finset, A. Coding patient emotional cues and concerns in medical consultations: the VeRona COding Definitions of Emotional Sequences (VR-CoDES). Patient Education I K Counseling: 2011, 82(2), 141-148

[6] C.G. Shields, R.M. Epstein, P. Franks, K. Fiscella, P. Duberstein and S.H. McDaniel et al., Emotion language in primary care encounters: reliability and validity of an emotion word count coding system, Patient Educ Couns 57 (2005), pp. 232-238.

[7] R. Zachariae, C.G. Pedersen, A.B. Jensen, E. Ehrnrooth, P.B. Rossen and H. von der Maase, Association of perceived physician communication style with patient satisfaction, distress, cancer-related self-efficacy, and perceived control over the disease, Brit J Cancer 88 (2003), pp. 658-665.

[8] R. Uitterhoeve, J. Bensing, E. Dilven, R. Donders, P. deMulder and T. van Achterberg, Nurse-patient communication in cancer care: does responding to patient's cues predict patient satisfaction with communication, Psycho-Oncology 18 (2009), pp. 1060-1068.

[9] H.B. Beckman and R.M. Frankel, The effect of physician behaviour on the collection of data, Ann Int Med 101 (1984), pp. 692-696.

[10] W.T. Branch and T.K. Malik, Using 'windows of opportunities' in brief interviews to understand patients' concerns, J Am Med Assoc 269 (1993), pp. 1667-1668. V

[11] P. Maguire, A. Faulkner, K. Booth, C. Elliot and V. Hillier, Helping cancer patients disclose their concerns, Eur J Cancer 32 (1996), pp. 78-81.

[12] J.D. Robinson, Closing medical encounters: two physician practices and their implications for the expression of patients' unstated concerns, Soc Sci Med 53 (2001), pp. 639-656.

[13] F. Lang, M.R. Floyd, K. Beine and P. Buck, Sequenced questioning to elicit patient's perspective on illness: effects on information disclosure, patient satisfaction, time expenditure, Fam Med 43 (2002), pp. 325-330.

[14] D. Goldberg, L. Jenkins, T. Miller and E.B. Faragher, The ability of trainee general practitioners to identify psychological distress among their patients, Psychol Med 23 (1993), pp. 185-193.

[15] L. Del Piccolo, A. Saltini, C. Zimmermann and G. Dunn, Differences in verbal behaviours of patients with and without emotional distress during primary care consultations, Psychol Med 30 (2000), pp. 629643.

[16] L. Fallowfield, D. Ratcliffe, V. Jenkins and J. Saul, Psychiatric morbidity and its recognition by doctors in patients with cancer, Brit J Cancer 84 (2001), pp. 1011-1015.

[17] R.F. Brown, P.N. Butow, M. Henmann, S.M. Dunn, F. Boyle and M.H. Tattersall, Responding to the active and passive patient: Flexibility is the key, Health Expectations 5 (2002), pp. 236-245.

[18] C.L. Bylund and G. Makoul, Empathic communication and gender in the physician-patient encounter, Patient Educ Couns 48 (2002), pp. 207-216.

[19] R.L. Street, Communicative styles and adaptations in physician-parent consultations, Soc Sci Med 34 (1992), pp. 1155-1163.

[20] D.L. Roter, The Roter method of interaction process analysis: RIAS manual, The John's Hopkins University, Baltimore (1993).

[21] P.N. Butow, S.M. Dunn, M.H.N. Tattersall and Q.J. Jones, Computer-based interaction analysis of the cancer consultation, Brit J Cancer 71 (1995), pp. 115-121.

[22] Heaven C, Green C. Medical Interview Aural Rating Scale. Unpublished report. CRUK Psychological Medicine Group, University of Manchester; 1999.

[23] S. Ford, A. Hall, D. Ratcliffe and L. Fallowfield, The Medical Interaction Process System (MIPS): an instrument for analyzing interview of oncologists and patients with cancer, Soc Sci Med 50 (2000), pp. 553-566.

[24] L. Del Piccolo, S.M. Putnam, M.A. Mazzi and C. Zimmermann, The biopsychosocial domains and the functions of the medical interview in primary care: construct validity of the Verona Medical Interview Classification System, Patient Educ Couns 53 (2004), pp. 47-56.

[25] C. Zimmermann, L. Del Piccolo and A. Finset, Cues and concerns by patients in medical consultations. A literature review, Psychol Bull 133 (2007), pp. 438-463.

[26] G. Humphris, Verona Network on Sequence Analysis, Patient Educ Couns 53 (2004), pp. $247-250$.

[27] L. Del Piccolo, C. Goss and C. Zimmermann, The third meeting of the Verona Network on Sequence Analysis. Finding common grounds in defining patient cues and concerns and the appropriateness of provider responses, Patient Educ Couns 57 (2005), pp. 241-244.

[28] L. Del Piccolo, C. Goss and S. Bergvik, The fourth meeting of the Verona Network on Sequence Analysis "Consensus finding on the appropriateness of provider responses to patient cues and concerns", Patient Educ Couns 61 (2006), pp. 473-475.

[29] Bergvik S, Del Piccolo L. The fifth meeting (2007) of the Verona Network on Sequence Analysis "Coding of health provider talk to patient cues and concerns" (http://www.each.eu).

[30] D.L. Roter, S.M. Larson, M.C. Beach and L.A. Cooper, Interactive and evaluative correlates of dialogue sequence: a simulation study applying the RIAS to turn taking structures, Patient Educ Couns 71 (2008), pp. 26-33. 
Zimmermann, C., Piccolo, L. del, Bensing, J., Bergvik, S., Haes, H. de, Eide, H., Fletcher, I., Goss, C., Heaver C., Humphris, G., Young-Mi, K., Langewitz, W., Meeuwesen, L., Nuebling, M., Rimondini, M., Salmon, P. Dulmen, S. van, Wissow, L., Zandbelt, L., Finset, A. Coding patient emotional cues and concerns in mealical consultations: the VeRona COding Definitions of Emotional Sequences (VR-CoDES). Patient Educationl_k Counseling: 2011, 82(2), 141-148

[31] W.B. Stiles, Describing talk: a taxonomy of verbal response modes, Sage, Newbury Park (1992).

[32] P. Ekman and W.V. Friesen, The repertoire of nonverbal behavior: categories, origins, usage, and encoding, Semiotica 1 (1969), pp. 49-98.

[33] M. Stewart, J.B. Brown, A. Donner, I.R. McWhinney, J. Oates and W.W. Weston et al., The impact of patient-centered care on outcomes, J Fam Pract 49 (2000), pp. 796-804.

[34] P. Little, H. Everitt, I. Williamson, G. Warner, M. Moore and C. Gould et al., Observational study of effect of patient centredness and positive approach on outcomes of general practice consultations, $\mathrm{Br}$ Med J 323 (2001), pp. 908-911.

[35] S.B. Detmar, N.K. Aaronson, L.D.V. Wever, M. Muller and J.H. Schornagel, How are you feeling? Who wants to know? Patients' and oncologists' preferences for discussing health-related quality-of-life, J Clin Oncol 13 (2000), pp. 3295-3301.

[36] D. Goldberg and P. Williams, The user's guide to the general health questionnaires, NFER-Nelson, Windsor (1988).

[37] A.M. Van Dulmen, M. Nübling and W. Langewitz, Doctors' responses to patients' concerns: an exploration of communication sequences in gynaecology, Epidemiol Psichiatr Soc 12 (2003), pp. 98-102.

[38] L.C. Zandbelt, E.M.A. Smets, F.J. Oort, M.H. Godfried and J.C.J.M. de Haes, Patient participation in the medical specialist encounter: does physicians' patient-centred communication matter?, Patient Educ Couns 65 (2007), pp. 396-406.

[39] L. Del Piccolo, H. de Haes, C. Heaven, J. Jansen, W. Verheul and J. Bensing et al., Coding provider responses to cues and concerns, Development of the Verona CoDES-P framework. Patient Educ Couns; (2010) 10.1016/j.pec.2010.02.024 in this issue.

[40] G. Jefferson and J. Lee, The rejection of advice: managing the problematic convergence of a troublestelling' and a 'service encounter'. In: P. Drew and J. Heritage, Editors, Talk at work, Cambridge University Press, Cambridge (1992), pp. 521-548.

[41] J. Ruusuvuori, 'Empathy' and 'sympathy' in action: attending to patients' troubles in Finnish homeopathic and general practice consultations, Soc Psychol Quart 68 (2005), pp. 204-222.

[42] Y.M. Kim, A. Kols, S. Prammawat and W. Rinehart, Sequence analysis: responsiveness of doctors to patient cues during Family planning consultations in Mexico, Patient Educ Couns 58 (2005), pp. 114-117.

[43] H. Eide, R. Frankel, A.C.B. Haaversen, K.A. Vaupel, P. Graugaard and A. Finset, Listening for feelings. Identifying and coding empathic and potential empathic opportunities in medical dialogues, Patient Educ Couns 54 (2004), pp. 291-297.

[44] L. Meeuwesen, C. Schnap and C. van der Strak, Verbal analysis of doctor-patient communication, Soc Sci Med 32 (1991), pp. 1143-1150. 
Zimmermann, C., Piccolo, L. del, Bensing, J., Bergvik, S., Haes, H. de, Eide, H., Fletcher, I., Goss, C., Heaver), C., Humphris, G., Young-Mi, K., Langewitz, W., Meeuwesen, L., Nuebling, M., Rimondini, M., Salmon, P. Dulmen, S. van, Wissow, L., Zandbelt, L., Finset, A. Coding patient emotional cues and concerns in medical consultations: the VeRona COding Definitions of Emotional Sequences (VR-CoDES). Patient EducatiळhIKE Counseling: 2011, 82(2), 141-148

\section{TABLES}

Table 1

List of 10 coding systems applied in the comparative coding exercise of 2004 to the transcripts of four general practice and two oncology consultations.

\begin{tabular}{|c|c|c|}
\hline Coding instrument and definitions & Author & Coders \\
\hline $\begin{array}{l}\text { Roter interaction Analysis (RIAS) } \\
\text { Concern: Statement or non-verbal expression indicating that a condition or } \\
\text { event is serious, worrisome, distressing or deserving special attention, including } \\
\text { emotional description of medical situation or descriptions of non-specific feelings }\end{array}$ & $\begin{array}{l}\text { Roter [20] } \\
\text { Van Dulmen et al. [37] }\end{array}$ & $\begin{array}{l}\text { Sandra van Dulmen, } \\
\text { Wolf Langewitz }\end{array}$ \\
\hline $\begin{array}{l}\text { Medical Interview Aural Rating Scale (MIARS) } \\
\text { Cue: A hint or clear expression that something is a may be important or } \\
\text { distressing or a cause of concern } \\
\text { Concern: A patient-generated issue for which there is evidence of current importance, } \\
\text { a clear mention of feeling, or a clear psychological focus and naming of emotion }\end{array}$ & Heaven and Green [22] & Cathy Heaven, Ian Fletcher \\
\hline $\begin{array}{l}\text { Patient-centred Behaviour Coding Instrument (PBCI) } \\
\text { Cue: An utterance which expresses in an indirect way patient's concern, anxiety, } \\
\text { anger, frustration or other negative emotions, signalling patients' need for } \\
\text { information or emotional support. It gives the doctor an opportunity to pursue } \\
\text { the matter further, but it is not an overt request } \\
\text { Concern: Utterances in which the patient expresses in a direct manner concern, } \\
\text { anxiety, anger, frustration or other negative emotions }\end{array}$ & Zandbelt et al. [38] & Linda Zandbelt, Ellen Smets \\
\hline $\begin{array}{l}\text { Verona Medical Interview Classification System (VR-MICS) } \\
\text { Psychological cue: any expression by patient introducing a new content referring to } \\
\text { feelings, ideas, somatic or emotional worries not yet explored or dealt with by the provider }\end{array}$ & Del Piccolo et al. [24] & Lidia Del Piccolo \\
\hline $\begin{array}{l}\text { Conversation Analysis (based on Gail Jefferson's findings on troubles-telling sequences) } \\
\text { outright expression of emotion or concern (worried, unhappy). } \\
\text { extreme case formulation on own negative experience, } \\
\text { negative observation on own situation and } \\
\text { questioning someone's actions in relation to own situation }\end{array}$ & $\begin{array}{l}\text { Jefferson and Lee [40] } \\
\text { Ruusuvuori }[41]\end{array}$ & Johanna Ruusuvuori \\
\hline $\begin{array}{l}\text { Psychological Distress in Oncology Classification } \\
\text { Emotional cue: statement to signal the need for emotional support rated according to intensity }\end{array}$ & Butow et al. [3] & Phyllis Butow \\
\hline $\begin{array}{l}\text { Empathic Communication Coding System (ECCS) } \\
\text { Empathic opportunity: } \\
\text { statement of emotion: expression of a current emotion of sorrow, fear, hate and similar } \\
\text { statement of challenge: expression of the negative effect of a physical or psychosocial problem }\end{array}$ & Bylund and Makoul [18] & Greg Makoul, Carma Bylund \\
\hline $\begin{array}{l}\text { Provider Responsiveness in Client Active Communication } \\
\text { Emotional cue: Any verbal expression indicating a need for an emotional response, } \\
\text { including direct statements of worry, anxiety and confusion }\end{array}$ & Kim et al. [42] & Young-Mi Kim \\
\hline $\begin{array}{l}\text { Empathic and Potential Empathic Opportunity Method (E-PE-O) } \\
\text { Empathic opportunity: direct and explicit description of an emotion } \\
\text { Potential empathic opportunity: indirect statement from which to infer an } \\
\text { underlying emotion that has not been clearly expressed }\end{array}$ & $\begin{array}{l}\text { Suchman et al. [1] } \\
\text { Eide et al. [43] }\end{array}$ & Arnstein Finset, Hilde Eide \\
\hline $\begin{array}{l}\text { RIAS combined with Verbal Response Mode System (VRM) } \\
\text { Disclosure: expressions revealing thoughts, feelings, perceptions or intentions }\end{array}$ & $\begin{array}{l}\text { Stiles [30] } \\
\text { Meeuwesen et al. [44] }\end{array}$ & Ludwien Meeuwesen \\
\hline
\end{tabular}


Zimmermann, C., Piccolo, L. del, Bensing, J., Bergvik, S., Haes, H. de, Eide, H., Fletcher, I., Goss, C., Heaver, C., Humphris, G., Young-Mi, K., Langewitz, W., Meeuwesen, L., Nuebling, M., Rimondini, M., Salmon, P. Dulmen, S. van, Wissow, L., Zandbelt, L., Finset, A. Coding patient emotional cues and concerns in meditod consultations: the VeRona COding Definitions of Emotional Sequences (VR-CoDES). Patient Educatiol_k Counseling: 2011, 82(2), 141-148

\section{Table 2}

Coding exercises 2005-2007.

Coding exercise with the first consensus definitions 2005-2006

Fourteen coders applied a first version of the consensus definitions to one transcript of an oncology consultation transcript. The coders were Lidia Del Piccolo, Hilde Eide, Ian Fletcher, Gerry Humphris, Young-Mi Kim, Ludwien Meeuwesen, Michela Rimondini, Johanna Ruusovuori, Peter Salmon, Sandra van Dulmen, William Verheul, Larry Wissow, Linda Zandbelt and Christa Zimmermann.

Coding exercise with revised consensus definitions 2006

Nine raters applied the revised Consensus definitions to the same six consultation transcripts of the comparative coding exercise (see Table 1). The coders were Peter Salmon, Jozien Bensing, Gerry Humphris, Christa Zimmermann, Larry Wissow, Claudia Goss, Svein Bergvik, Jesse Jansen, William Verheul.

Four-centre pilot reliability study 2006-2007

Each centre conducted an inter-rater reliability study on transcribed or videotaped consultations from their own setting. The coders were Hilde Eide and Tonje Sibbern (Oslo), Linda Zandbelt and Sanne Franssen (Amsterdam), William Verheul and Jesse Jansen (Utrecht), Christa Zimmermann and Lidia Del Piccolo (Verona).

Appendix A. VR-CoDES CC Summary table

\begin{tabular}{|c|c|c|}
\hline Expression & Definitions & $\begin{array}{l}\text { Health provider-elicited (HPE) } \\
\text { Patient-elicited (PE) }\end{array}$ \\
\hline $\begin{array}{l}\text { CONCERN } \\
\text { Clear verbalisation of an unpleasant } \\
\text { emotional state }\end{array}$ & $\begin{array}{l}\text { Emotion is current or recent and } \\
\text { issue of importance is not stated. } \\
\text { Issue of recent or current importance is } \\
\text { stated (life events, social problems, } \\
\text { symptoms, other issues). }\end{array}$ & $\begin{array}{l}\text { HPE D: You look worried! P: Yes doctor, I am quite worried } \\
\text { PE P: And then...I also feel very depressed } \\
\text { HPE D: What are you worried about? } \\
\text { P: That I could lose my baby } \\
\text { P: You are right, I am upset about the bad outcome of the treatment } \\
\text { D: Are you worried about the test results? P: Yes I am } \\
\text { PE P: Now the headaches are not so bad. . but I am worried } \\
\text { about the results of the tests }\end{array}$ \\
\hline $\begin{array}{l}\text { CUE } \\
\text { Expression in which the emotion is not } \\
\text { clearly verbalized or might be present } \\
\text { The criteria of currency/recentness is } \\
\text { not applicable }\end{array}$ & $\begin{array}{l}\text { a. Words or phrases in which the } \\
\text { patient uses vague or unspecified } \\
\text { words to describe his/her emotions. } \\
\text { b. Verbal hints to hidden concerns } \\
\text { (emphasizing, unusual words, unusual } \\
\text { description of symptoms, profanities, } \\
\text { metaphors, ambiguous words, double negatives, } \\
\text { exclamations, expressions of uncertainties } \\
\text { and of hope regarding stated problems). } \\
\text { c. Words or phrases which emphasize } \\
\text { (verbally or non-verbally) physiological or } \\
\text { cognitive correlates (regarding sleep, appetite, } \\
\text { physical energy, concentration, excitement } \\
\text { or motor slowing down, sexual desire) of } \\
\text { unpleasant emotional states. } \\
\text { d. Neutral words or phrases that mention issues } \\
\text { of potential emotional importance which stand } \\
\text { out from the narrative background and refer } \\
\text { to stressful life events and conditions. } \\
\text { e. A patient-elicited repetition of a previous neutral } \\
\text { expression (repetitions of a neutral expression } \\
\text { within the same turn are not included). } \\
\text { f. Non-verbal expressions of emotion. } \\
\text { g. Clear expression of an unpleasant emotion, } \\
\text { which occurred in the past (more than } 1 \text { month } \\
\text { ago) or is without time frame. }\end{array}$ & $\begin{array}{l}\text { HPE D: How do you feel? P: I feel so so (a) } \\
\text { D: How do you feel? P: It could be better (a) } \\
\text { D: How do you feel? P: I feel like a wet rag (b) } \\
\text { D: How is the pain? P: The pain really stabs me (b) } \\
\text { D: How is it going? P: The last } 2 \text { months I had only } \\
\text { sleepless nights (c) } \\
\text { D: How is your appetite? P: I force myself to eat (c) } \\
\text { D: What else? P: I just had this sad funeral... (d) } \\
\text { D. What did Dr. X said to you? P: Well... (sighs)... he } \\
\text { told me that I have cancer (d) } \\
\text { D: How do you feel? P: Silence (crying, sighing) (f) } \\
\text { PE D: How is your husband? P: He is always so nervous... I } \\
\text { do not feel good about him (a) } \\
\text { D: Are you anxious? P: I am (Concern), but the worse thing } \\
\text { is that everything seems useless (b) } \\
\text { D: It takes some time to get to sleep... P: Yeah, .... And then in } \\
\text { fact once you are pregnant you, well, do feel very tired and just } \\
\text { feel very exhausted, which is not the first time as well. (b) } \\
\text { D: What about the waterworks? P: That's ok. I have this stabbing } \\
\text { pain in my back (b) } \\
\text { D: Wouldn't it be useful if you had some time off? P: I don't } \\
\text { think I could have some time off. because they're very, very... (b) } \\
\text { D: How is your appetite? P: I don't eat so much lately, and I feel } \\
\text { completely without energy (c) } \\
\text { P: You know that I can't relax, yeah (pause) Can't seem to just } \\
\text { relax (pause) (c) } \\
\text { D: Is your work tiring? P: Besides, there is my little girl. She goes } \\
\text { to a crecche now... (d) } \\
\text { P: I worked till I started radiation D: The weight is steady? } \\
\text { P: It has dropped about three kilos in the last fortnight, but then } \\
\text { maybe, because of the radiation... (e) } \\
\text { P: And (pause) ...patient cries (f) } \\
\text { P: When the doctor told me about the cancer I was so frightened (g) }\end{array}$ \\
\hline
\end{tabular}

